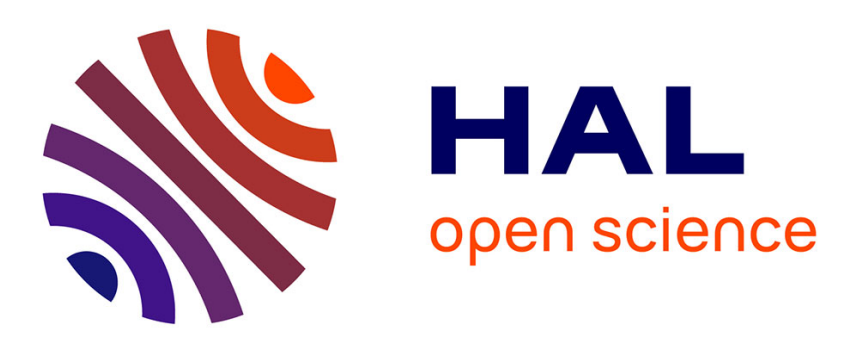

\title{
An SVD approach to reaching tasks based on cartesian geodesics
}

\author{
Adrien Datas, Pascale Chiron, Jean-Yves Fourquet
}

\section{To cite this version:}

Adrien Datas, Pascale Chiron, Jean-Yves Fourquet. An SVD approach to reaching tasks based on cartesian geodesics. Computer Methods in Biomechanics and Biomedical Engineering, 2013, Vol. 16, pp. 63-65. 10.1080/10255842.2013.815926 . hal-00881051

\section{HAL Id: hal-00881051 https://hal.science/hal-00881051}

Submitted on 12 Nov 2013

HAL is a multi-disciplinary open access archive for the deposit and dissemination of scientific research documents, whether they are published or not. The documents may come from teaching and research institutions in France or abroad, or from public or private research centers.
L'archive ouverte pluridisciplinaire HAL, est destinée au dépôt et à la diffusion de documents scientifiques de niveau recherche, publiés ou non, émanant des établissements d'enseignement et de recherche français ou étrangers, des laboratoires publics ou privés. 


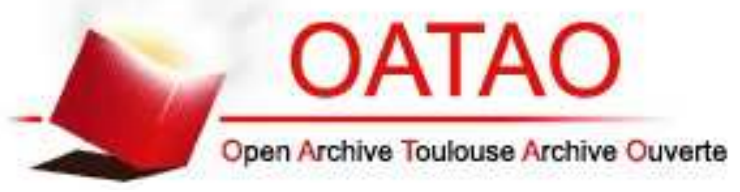

\section{Open Archive Toulouse Archive Ouverte (OATAO)}

OATAO is an open access repository that collects the work of Toulouse researchers and makes it freely available over the web where possible.

This is an author-deposited version published in: http://oatao.univ-toulouse.fr/ Eprints ID: 9430

To link to this article: DOI:10.1080/10255842.2013.815926

http://www.tandfonline.com/doi/full/10.1080/10255842.2013.815926

\section{To cite this version:}

Datas, Adrien and Chiron, Pascale and Fourquet, Jean-Yves An SVD approach to reaching tasks based on cartesian geodesics. (2013) Computer Methods in Biomechanics and Biomedical Engineering, Vol. 16 $\left(\mathrm{n}^{\circ} 1\right) \cdot \mathrm{pp} .63-65$. ISSN 1025-5842 


\title{
An SVD approach to reaching tasks based on Cartesian geodesics
}

\author{
A. Datas, P. Chiron, J-Y. Fourquet ${ }^{*} \dagger$ \\ $†$ LGP-ENIT, Université de Toulouse
}

Keywords: upper-limb; reaching; optimal control; simulation; SVD

\section{Introduction}

We are interested in human motion characterization and automatic motion simulation. The apparent redundancy of the humanoid w.r.t its explicit tasks lead to the problem of choosing a plausible movement in the framework of redundant kinematics. This work explores the intrinsic relationships between singular value decomposition at kinematic level and optimization principles at task level and joint level. The motivation is not to neglect dynamics - essential in whole-body equilibrium for instance - but to describe a simple framework for plausible human-like motion generation, when dynamics are not decisive. The ideas are tested on sitting reach motions, for both translations and rotations task components.

Optimization principles have been studied in human motion literature and in particular the reach motion. The main idea is that humans favor a path in task space such that the distance to the target monotonously decreases and, even more, that the hand follows the shortest path (Engelbrecht 2001). But, several authors have shown that the reference path is not always a straight line and some of them attempted to define new criteria in order to explain these discrepancies. On the one hand, one may think that the human locomotor apparatus is really efficient and is able to follow the most efficient paths in Cartesian world: the straight line. On the other hand, we know that kinematic chains are not isotropic motion generators in Cartesian space. Thus, one can infer that there is a preferred workspace zone in which the path is a straight line, and other zones in which the mechanical constraints induced by the nature of kinematic chains will render really difficult to follow a straight line.

Here, the matter is not so much to ask if optimization principles act in Cartesian space or in joint space but rather how to reproduce a trade-off between the task efficiency and the constraints induced by the mechanical structure.

\section{Methods}

Cartesian motion can be written as a function of joint coordinates and at kinematic level it writes as a linear map:

$$
\delta X=J(q) \delta q
$$

where $\boldsymbol{J}(\boldsymbol{q})$ is the $m \times n$ Jacobian matrix mapping joint velocities to Cartesian velocities. This mapping is configuration-dependent and does not provide an isotropic transformation from joint space to task space. The properties of this mapping are enlightened by its singular value decomposition (SVD) (Golub et al. - 1983). SVD provides the means to analyze the amount of joint displacement necessary to move in a given direction in task space. SVD of J writes: $J=U \Sigma V^{t}$

where $U=\left[U_{1} U_{2} \cdots U_{m}\right]$ is an orthonormal basis of the tangent vectors to the task space, $V=\left[V_{1} V_{2} \cdots V_{n}\right]$ is an orthonormal basis of the tangent space to the configuration space, $\Sigma$ is a $m \times n$ diagonal matrix and the singular values $\sigma_{i}$ of $\boldsymbol{J}$ are arranged such that $\sigma_{1} \geq \sigma_{2} \geq \cdots \geq \sigma_{m} \geq 0$.

The geometrical meaning of this decomposition is: $\boldsymbol{J}$ maps a unit ball in the tangent space to the configuration space into an m-dimensional ellipsoid in the tangent space to the task space. This ellipsoid has principal axes $U_{i}$ with length $\sigma_{i}$. Thus, a significant difference of value among the $\sigma_{i}$ implies that, for a given norm of displacement in task space, the amount of joint displacement varies with the direction and that some directions in task space are really easier to follow.

The classical solution of (1) by pseudo-inversion writes $\delta q^{+}=J^{+} \delta X$ with $J^{+}=V \Sigma^{+} U^{t}$ and thus:

$$
\delta \tilde{q}_{i}^{+}=\frac{1}{\sigma_{i}} \delta \tilde{X}_{i} \text { with } \delta \tilde{q}_{i}^{+}=V_{i}^{t} \delta q^{+} ; \delta \tilde{X}_{i}=U_{i}^{t} \delta X
$$

This principle is used in order to produce a simulation of what happens when human motion discards the motion components in the directions of the small $\sigma_{i}$. Then, a weighted pseudo-inversion scheme is provided that takes the classical form

$$
J_{W}^{+}=W^{-1} J^{t}\left(J W^{-1} J^{t}\right)^{-1}
$$

where $\boldsymbol{W}$ is the $n \times n$ inertia-weighting matrix when the singular values remains above a given value. This scheme is adapted by filtering some Cartesian components when the associated singular values are under a given threshold:

$$
J_{W}^{+}=W^{-1} J^{t}\left(J W^{-1} J^{t}+F\right)^{-1}
$$

where $\boldsymbol{F}$ is the $m \times m$ filtering matrix computed by:

$$
F=\sum_{i} \alpha_{i} U_{i} U_{i}^{t}
$$

This filtering introduces a deviation from the Cartesian geodesics based on the cost in joint space. 


\section{Results and Discussion}

The simulations are realized with a 24 degrees of freedom virtual human upperbody made from ideal rotoid joint and rigid bodies (Hue et al. - 2008). The approach has been explored for reaching motions in the frontal and sagittal planes, for imposed initial positions and orientations. For the automatic motion generation, the initial reference trajectory was always the geodesics in $\mathrm{R}^{3}$ (straight lines) and the geodesics of $\mathrm{SO} 3$ for the orientation. Then the filtered pseudo-inversion scheme has been applied. An example on a classical experiment of Morasso (Morasso - 1981) revisited by adding orientation constraints (Figure 1) on the sequence EBDFCEAF illustrates the approach.

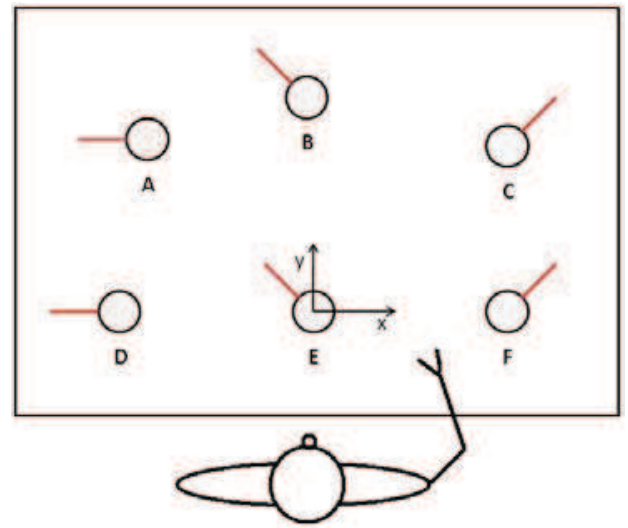

Figure 1. Description of the experiment

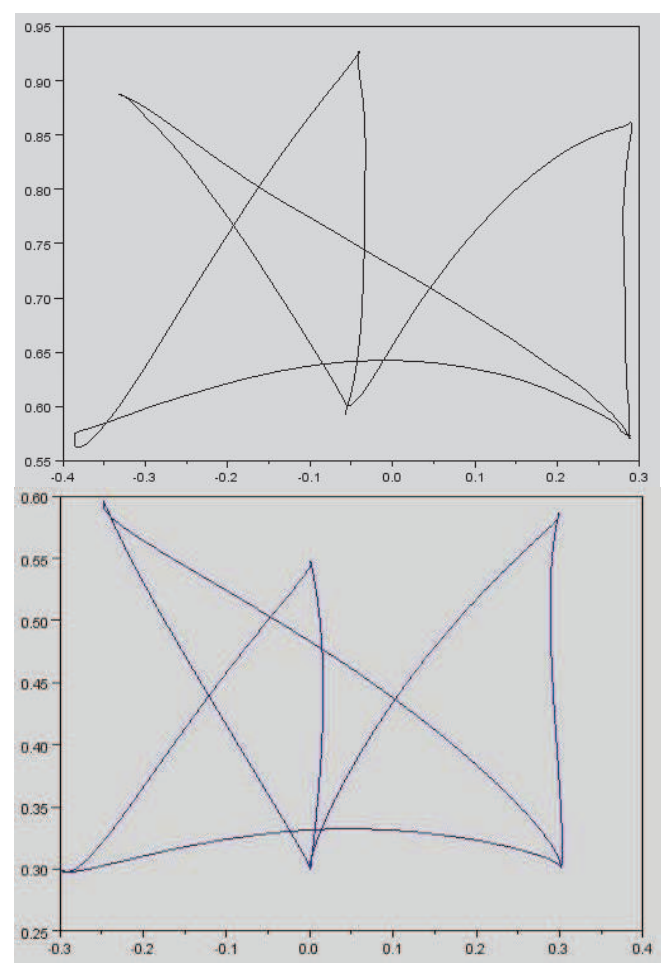

Figure 2. Motion capture (top) and simulation (bottom) of hand path.

The translation path obtained by motion capture and simulation are presented in figure 2 where it is shown that singular value filtering provides a way to reproduce human motion while satisfying endpoints constraints.

Coupling translation and rotation opens various questions and in particular because $\mathrm{SO} 3$ and $\mathrm{R}^{3}$ associated metrics are, by nature, different. Singular values are related to these metrics and then particular tuning of translation versus rotation parts is a matter of choice. Embedding this technique within a logic of prioritized tasks (translation prior to rotation e.g.) opens others perspectives and adds corresponding complexity in the analysis. Moreover it allows for different tuning of each components leading to parameters adapted to each metrics. The obtained simulated motion are closer to the captured ones.

\section{Conclusions}

Introducing singular value filtering along geodesics of Cartesian motion may explain the spatial path in captured human motion. It takes into account cost in both Cartesian and Joint space since it favors shortest paths in Cartesian space and limits the displacement in joint space. A similar approach could be promising for force generation analysis (Rezzoug et al - 2012). The SVD is also a useful tool that could help in understanding coupling of several tasks in human or humanoid motion (Saab et al-2012).

\section{References}

Engelbrecht SA. 2001. Minimum principles in motor control. Journal of Mathematical psychology, 45:497-542.

Golub GH., Van Loan CF. 1983. Matrix computations. John Hopkins studies in Math. Sciences.

Hue V, Fourquet J-Y, Chiron P. 2008. On realistic human motion Simulation for Virtual Manipulation Tasks", 10th IEEE Int. Conf. on Control, Automation, Robotics and Vision (ICARCV'08), Hanoi, Vietnam, 162-172, december 17-20.

P. Morasso 1981. Spatial control of arm movements. Experimental brain research, 42:223-227.

Rezzoug, N, Jacquier-Bret J, Hernandez V, Gorce P. 2012. Biomechanical versus robotic indices to assess isometric forces generation capabilities, Computer Methods in Biomechanics and Biomedical Engineering, 15(S1):153-155.

Saab L, Soueres P, Mansard N, Fourquet J-Y. 2012. Generation of human-like motion on anthropomorphic systems using inverse dynamics, Computer Methods in Biomechanics and Biomedical Engineering, 15(S1):156-158. 